\title{
Effect of bis (tributyl tin) oxide on permeability of the blood-brain barrier: a transient increase
}

\author{
Kazuo Hara, Mitsuaki Yoshizuka, Yoshiaki Doi, Sunao Fujimoto
}

\begin{abstract}
Objectives-To study the effect of bis (tributyl tin) oxide (TBTO) on permeability of the blood-brain barrier.

Methods-Electron microscopy and an $x$ ray microanalyser with lanthanum chloride as a tracer were used, and blood tin concentrations were determined with an atomic absorption spectrophotometer. Adult male wistar rats received $0.05 \mathrm{ml} / \mathrm{kg}$ body weight of TBTO orally.

Results-A transient increase in paracellular permeability at the blood-brain barrier was found $2 \mathrm{~h}$ after the dose of TBTO. Electron dense lanthanum deposits penetrated tight junctions of the endothelia and permeated the subendothelial space. The $x$ ray microprobe data showed an accumulation of TBTO at the tight junctions at $2 \mathrm{~h}$. Leakage of tracer did not occur at $4 \mathrm{~h}$, but oedematous changes in the surrounding glial cells were prominent between 4 and $8 \mathrm{~h}$ and had almost returned to normal by $24 \mathrm{~h}$. By atomic absorption analysis, it was seen that blood tin concentrations rapidly increased at $1 \mathrm{~h}$ and rose to a maximum peak at $8 \mathrm{~h}$, then gradually decreased to reach zero at $24 \mathrm{~h}$.

Conclusions-Accumulated TBTO at tight junctions could have caused the temporary replacement of calcium ion by tin, which induces a transient increase in paracellular permeability throughout the blood-brain barrier.
\end{abstract}

(Occup Environ Med 1994;51:735-738)

Keywords: bis (tributyl tin) oxide, blood-brain barrier, capillary permeability, atomic absorption spectrophotometry

Department of of Occupational and Environmental Environmental Medicine, Kitakyushu 807

K Hara

Y Doi

$S$ Fujimoto

Department of

Anatomy, Kurume

University School of

Medicine, Kurume

830, Japan

M Yoshizuka

Correspondence to:

Dr Kazuo Hara,

Department of Anatomy,

University of Occupational

and Environmental Health,

and Environmental

Kitakyushu 807, Japan.

Accepted 22 June 1994

Tributyl tin compounds have been widely paints to prevent adhesions and growth of barnacles, algae, and other organisms on ship hulls, fishing nets, and cages. Recently, accumulation of tributyl tin, heavily toxic to marine organisms, has been pointed out in the food chain in crabs, oysters, salmon, and other fish. For instance, deformities such as dwarfism and kyphoscoliosis of young yellow tailed fish due to the toxic effects of tributyl tin compounds were reported. ${ }^{1}$ Although the toxic effects of these compounds on mammals have been given much attention from biochemical and pharmacological viewpoints, ${ }^{24}$ detailed ultrastructural investigations to clarify the aetiology of the toxicity of tributyl tin have been limited.

Neurotoxic effects of organotin compounds have been found in accidentally exposed humans. ${ }^{56}$ The signs and symptoms were severe headache, vomiting, vertigo, photophobia, anorexia, increased tendency to sleep, memory loss, and psychiatric disturbances. Striking interstitial oedema of the cerebral white matter was found in the victims, and reproduced as a specific effect of organotin compounds in experimental animals. ${ }^{78}$ The detailed mechanisms that cause the shift of the fluid into the central nervous system in organotin intoxications remains uncertain. Our study was undertaken to determine the effects of oral bis (tributyl tin) oxide (TBTO) on the permeability of the blood-brain barrier. We used an electron microscope and an $x$ ray microanalyser. Also, blood tin concentrations were measured with an atomic absorption spectrophotometer.

\section{Materials and methods}

ANIMALS

Adult male wistar UOEH rats (weight $250-300 \mathrm{~g}$ ) were housed in separate stainless steel cages and maintained in a 12 hour lightdark cycle. Exposure to light was six to 18 hours. Animals completed an 18 hour fast before the dose, but were permitted free access to water.

\section{ELECTRON MICROSCOPY}

In our preliminary study, ${ }^{9}$ we found that a single dose of $0.2 \mathrm{ml} / \mathrm{kg}(234 \mathrm{mg} / \mathrm{kg})$ body weight of TBTO given orally was the $\mathrm{LD}_{50}$ used in the fishing industry as antifouling agents in numerous formulations of marine

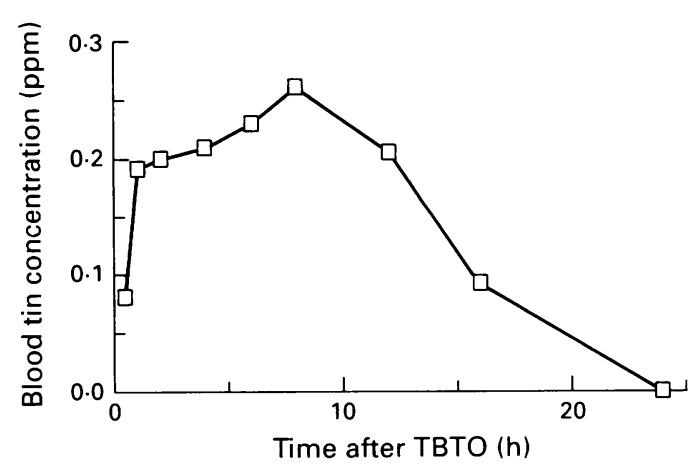

Figure 1 Mean blood tin concentrations after treatment with TBTO measured with an atomic absorption spectrophotometer. 


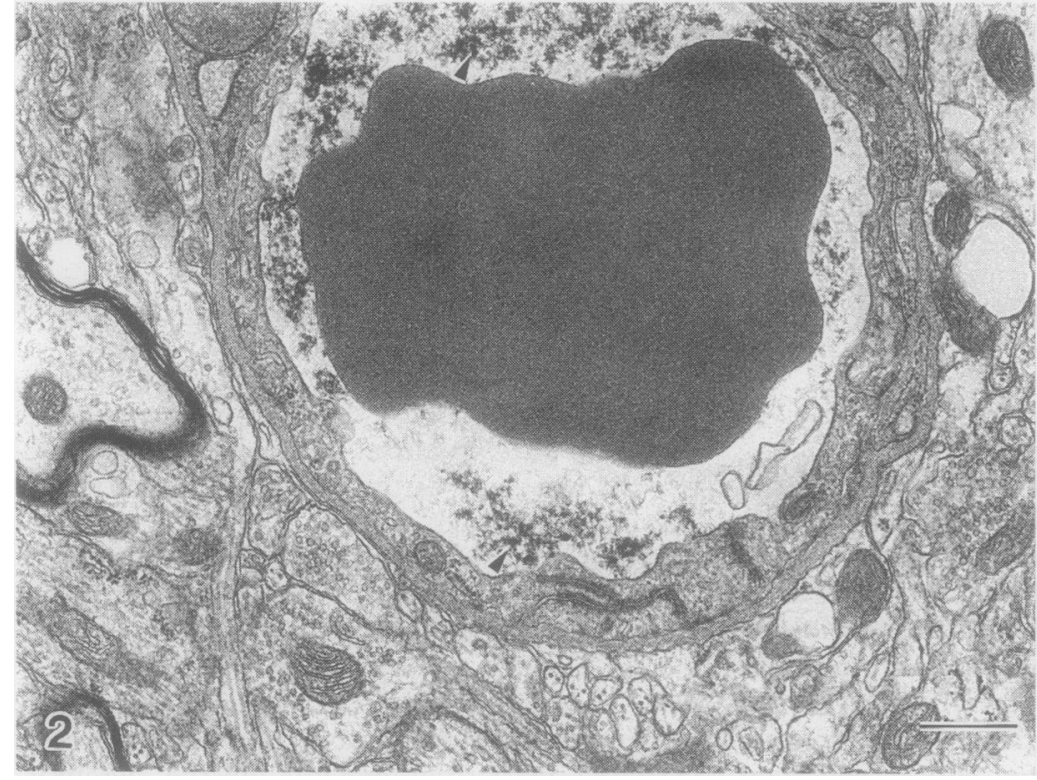

Figure 2 Lanthanum deposits (arrowheads) do not penetrate the capillary endothelium $1 \mathrm{~h}$ after TBTO treatment. Bar represents $0.5 \mu \mathrm{m}$.

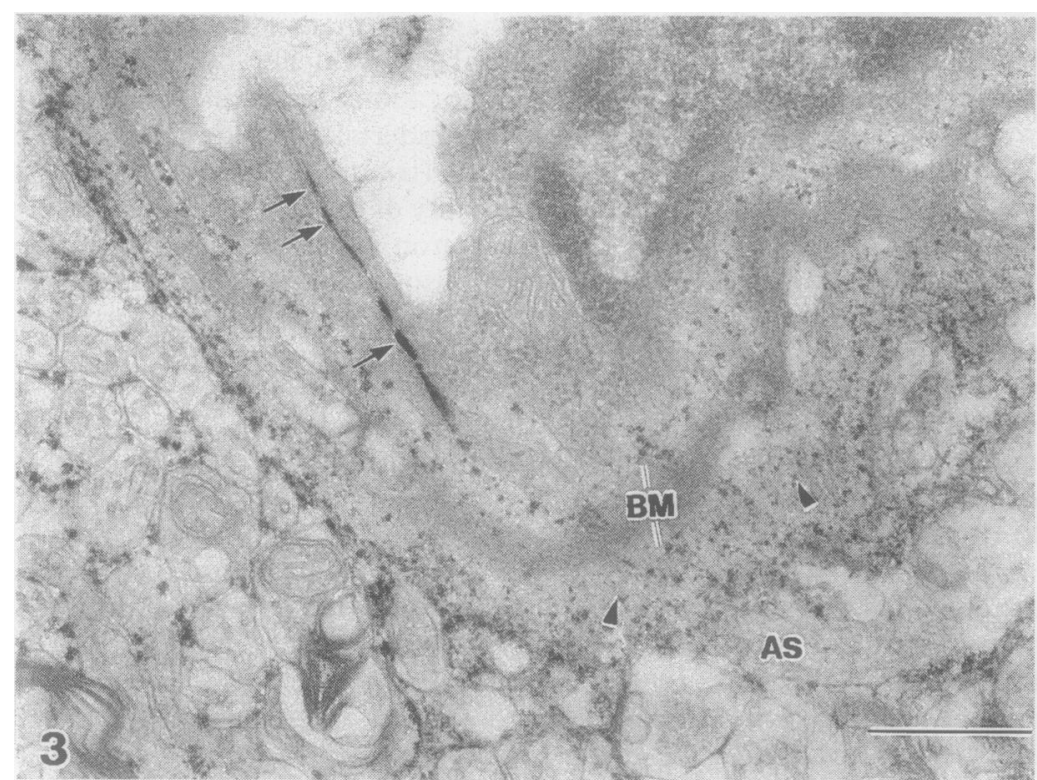

Figure 3 Tracer exists in the interendothelial space (arrows), the oedematous subendothelial space (arrowheads), and in the intercellular space of the endfeet of astrocytes (AS) that are occasionally separated from the basal lamina (BM). Bar represents $0.5 \mu \mathrm{m}$. all animals were deeply anaesthetised and perfused with $3.5 \%$ glutaraldehyde in $0.1 \mathrm{M}$ cacodylate buffer through the right common carotid artery. Then, each hypothalamus was isolated, further immersed in the same fixative, postfixed in $1 \%$ osmium tetroxide in the same buffer, dehydrated by acetone, and embedded in epoxy resin. Ultrathin sections were stained by uranyl acetate and lead citrate and viewed with a JEM 1200EX electron microscope.

\section{RAY MICROANALYSIS}

In the energy dispersive $x$ ray microanalysis, frozen sections of tissues are usually used for the detection of cytoplasmic elements. In our preliminary experiment, however, the tin Lalpha peak (3.44 keV) was completely covered by the high potassium $\mathrm{K}$-alpha peak $(3.31 \mathrm{keV})$ due to persistance of the intracytoplasmic potassium ion in the frozen section. Therefore, sections fixed and embedded in resin were used.

Non-stained ultrathin sections were analysed for detection of accumulations of TBTO in the hypothalamus with a JEM 2000EX electron microscope equipped with a LINK QX 200J energy dispersive $x$ ray microanalyser.

DETERMINATION OF BLOOD TIN

CONCENTRATIONS

Twenty four male wistar rats received the dose of TBTO orally. At $0.5,1,2,4,8,12$, 16 , and 24 hours after the dose three animals from each group were deeply anaesthetised with an injection of pentobarbitone, and blood samples were collected from the left ventricle. Whole blood was diluted fourfold with $3 \mathrm{~N} \mathrm{HCl}$ containing $10 \%$ ascorbic acid to prevent an adverse effect of iron when determining tin concentrations.

Tin concentrations in the blood samples were determined with a Hitachi Z-8000 Zeeman Atomic Absorption Spectrophotometer. To determine the blood tin concentrations, samples were dried at $80-120^{\circ} \mathrm{C}$ for $180 \mathrm{~s}$, ashed at $400-500^{\circ} \mathrm{C}$ for $60 \mathrm{~s}$, and atomised at $2700^{\circ} \mathrm{C}$ for $10 \mathrm{~s}$.

\section{Results}

No deaths or weight loss occurred among the experimental animals associated with TBTO treatment, and all treated rats seemed to be in good condition.

Figure 1 shows data obtained from atomic absorption analyses of tin concentrations in the blood samples. The blood tin concentration showed a rapid increase one hour after the dose. This rose to the maximum peak at eight hours, then gradually decreased, and reached unmeasurable concentrations at 24 hours.

By electron microscopy, it was seen that no ultrastructural changes occurred in the hypothalamus and that lanthanum chloride did not leak out of the true capillaries until one hour after treatment with TBTO (fig 2). The leakage of tracer through the tight junctions of the lanthanum chloride as a tracer through caudal vein. Five minutes after the injection, 


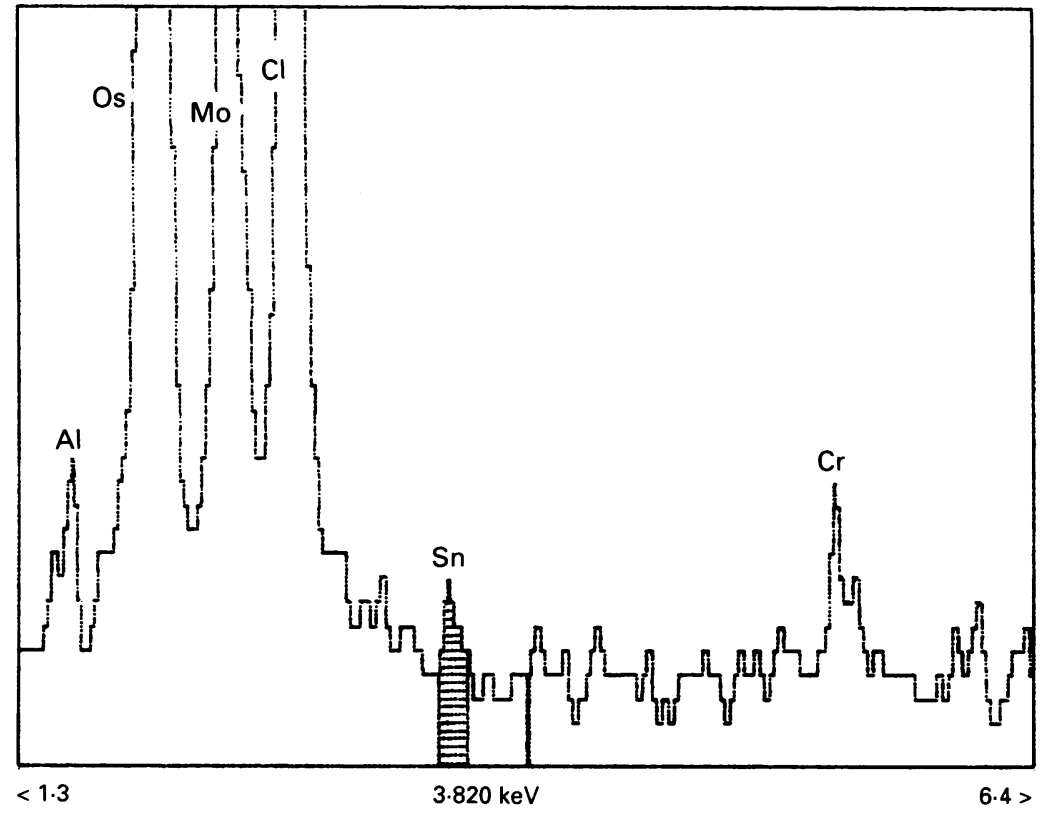

Figure 4 Tin L-alpha peak (3.44 keV) obtained from the leaky tight junction area of the capillary $2 \mathrm{~h}$ after TBTO treatment.

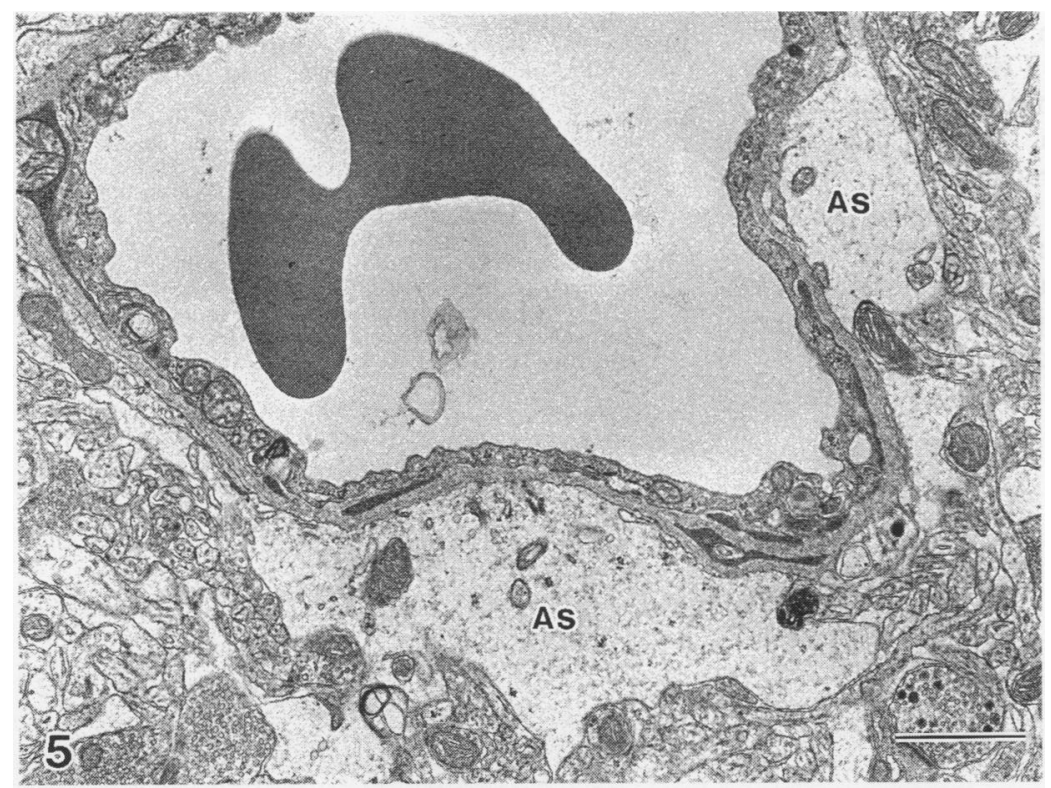

Figure 5 Astrocytes (AS) surrounding the capillary show severe oedematous changes at $8 \mathrm{~h}$ after TBTO treatment, whereas neural elements seem to be unaltered. Bar represents $1 \mu \mathrm{m}$. mic oedema of the glial cells surrounding the capillaries was prominent, whereas the neural elements did not seem to be affected. The tracer did not leak out of the capillaries and no degenerative changes were found in either endothelial cells or pericytes (fig 5). Moreover, the accumulation of TBTO at the tight junctions of the capillaries was not detected from four to eight hours after the dose. Oedematous changes in the surrounding glial tissue gradually became less pronounced and almost recovered by 24 hours after TBTO treatment (fig 6).

\section{Discussion}

As severe brain oedema was found in acute organotin intoxication in human cases, many experimental studies have been performed to clarify the aetiology of this phenomenon. The increase in cerebrovascular permeability to macromolecular tracers has not been reported. ${ }^{10}$ Therefore, the brain oedema induced by organotin compounds has been thought to be a cytotoxic and not a vasogenic oedema. ${ }^{11}$

The present tracer experiment clearly showed that an oral dose of TBTO induced a transient increase in the permeability of the blood-brain barrier of the true capillaries in the hypothalamus. The tight junctions temporarily opened very early after treatment with TBTO and resealed rapidly. This might be the reason why previous investigators could not find the opening in tight junctions.

The mechanisms that caused the opening of the blood-brain barrier brought about by TBTO are still unclear. The present $x$ ray microprobe data, however, indicated that TBTO preferentially accumulated at the leaking tight junctions. Although tight junctions are known to act as the main barrier to paracellular passage in epithelia, there do exist some structural differences in the depth and complexity of each tight junction. Claude and Goodenough classified so called tight junctions into "very tight" and "leaky tight" junctions. ${ }^{12}$ Machen et al in their in vitro experiments, reported that ionic lanthanum permeated the tight junction of isolated rabbit gall bladder and intestinal epithelia after immersion in an ionic lanthanum solution for one hour. ${ }^{13}$ They suggested that excess incubation in the ionic lanthanum solution might cause the alteration of the conformation of tight junction molecules and increase the paracellular permeability. It is therefore reasonable to assume that the accumulation of TBTO at our tight junctions may have had an effect on the configurations of the junctional complex molecules and this may have led to a change from "tight" to "leaky" during a limited period.

Recently, the existence of several $\mathrm{Ca}^{2+}$ dependent cell to cell adhesion molecules in vascular endothelial cells was verified. ${ }^{14}$ Prasada Rao et al reported that organotin compounds interfered with the transport of calcium ions into the sarcoplasmic reticulum in in vitro cardiac muscle cells. ${ }^{15}$ Taking these
Between four and eight hours after TBTO
Bexperiment. treatment, the intercellular and intracytoplas- 


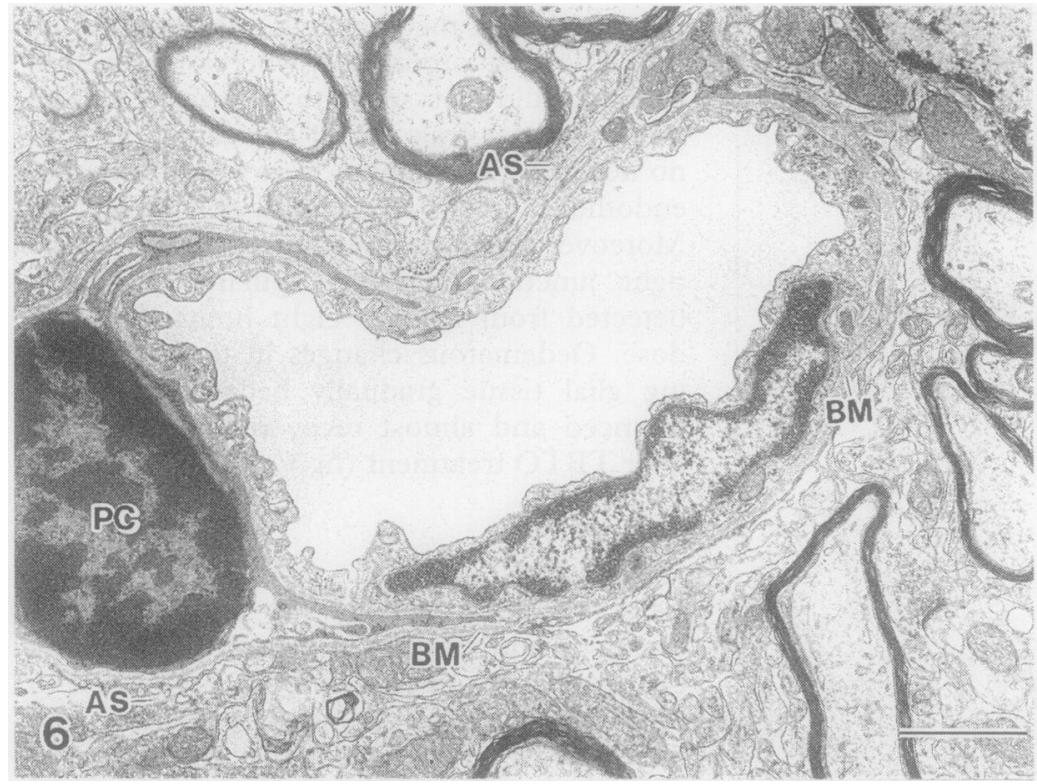

Figure 6 The oedematous changes of astrocytes (AS) have disappeared at 24 h after TBTO treatment. $P C=$ Pericyte; $B M=$ basal lamina. Bar represents $1 \mu \mathrm{m}$.

results into consideration, we consider at present that accumulated TBTO at the tight junctions caused the temporary replacement of calcium ion by tin, which induces a transient increase in paracellular ion permeability throughout the blood-brain barrier. Further studies are now in progress in our laboratory to elucidate the interactions of TBTO with calcium ions at the junctional complexes between the endothelial cells.
1 Boyer IJ. Toxicity of dibutyltin, tributyltin, and other organotin compounds to humans and to experimental animals. Toxicology 1989;55:253-98.

2 Organotin Environmental Programme Association. Toxicology and analytics of the tributyltins - the present status. Toxicology and analytics of the tributyltins-the present status. 1987. 1987

World Health Organization. Tributyltin compounds. Environmental health criteria Vol 116. Geneva: WHO 1990.

4 Henschler D. Tri-n-butyltin compounds. In: Henschler D, ed. Occupational toxicants: critical data evaluation for $M A K$ values and classification of carcinogens. Vol 1 . Weinheim: VCH Verlagsgesellschaft mbH, 1991; 315-33.

5 Alajouanine T, Dérobert L, Thiéfery S. Étude clinique d'ensemble de 210 cas d'intoxication par les sels organique d'etain. Rev Neurol (Paris) 1958;98:85-96.

6 Ross WD, Emmett EA, Steiner J, Tureen R. Neurotoxic effects of occupational exposure to organotins. $A m f$ Psychiatry 1981;138:1092-5.

7 Hirano A, Zimmerman HM, Levine S. Intramyelinic and extracellular spaces in triethyltin intoxication. $f$ Neuropathol Exp Neurol 1968;27:571-80.

8 Inoue $T$, Nagara $H$, Kondo A, Fukui $M$, Tateishi J. Effects of intracarotid hyperosmolar mannitol in triethyltin (TET)-induced rat brain edema-preservation of bloodbrain barrier (BBB) in TET edema. Brain Res 1987;414:309-13.

9 Yoshizuka M, Hara K, Doi Y, Mori N, Yokoyama M, Ono E, Fujimoto $S$. The toxic effects of bis (tributyltin) oxide on the rat thoracic aorta. Histol Histopathol 1992;7: 445-9.

10 Hultström D, Forssén M, Pettersson A, Tengbar C, Jarild $M$, Olsson Y. Vascular permeability in acute triethyltininduced brain edema studied with FITC-dextrans, induced brain edema studied with FITC-dextrans, sodium fluorescein and horseradish per
ers. Acta Neurol Scand 1984;69:255-63.

11 Hirano A. A guide to neuropathology. Tokyo: Igaku Shoin, 1992:1-473.

12 Claude P, Goodenough DA. Fracture faces of zonulae occludentes from "tight" and "leaky" epithelia. $f$ Cell Biol 1973;58:390-400

13 Machen TE, Erlij D, Wooding FBP. Permeable junctional complexes. The movement of lanthanum across rabbit gallbladder and intestine. $f$ Cell Biol 1972;54:302-12.

14 Heimark RL, Degner M, Schwartz SM. Identification of a $\mathrm{Ca}^{2+}$-dependent cell-cell adhesion molecule in endothelial cells. 7 Cell Biol 1990;110:1745-56.

15 Prasada Rao KS, Cameron JA, Yallapragada PR, Vig PJS Desaiah D. Inhibition of $\mathrm{Ca}^{2+}$ transport associated with Desaiah $\mathrm{D}$. Inhibition of $\mathrm{Ca}^{2+}$ transport associated with
cAMP-dependent protein phosphorylation in rat cardiac sarcoplasmic reticulum by triorganotins. Arch Toxicol
1991;65:311-7. 